\title{
PARTISIPASI MASYARAKAT DALAM MENCEGAH KEBAKARAN HUTAN DAN LAHAN DI DESA RASAU JAYA II KABUPATEN KUBU RAYA
}

\author{
(In Community Participation Prevening Forest Land Fire In Village Rasau Jaya II \\ Kubu Raya Regency)
}

\author{
Nopita Rahmah Nigrum, Emi Roslinda, Tri Widiastuti \\ Fakultas Kehutanan Universitas Tanjungpura Pontianak. Jl. Daya Nasional Pontianak 78124 \\ E-mail: nopita1610@yahoo.com
}

\begin{abstract}
Rasau Jaya Village, Kubu Raya district, which detected high hotspots annually. To prevent forest and land fires, community participation is needed. The purpose of this study was to analyze community participation in preventing forest and land fires, and to find out factors related to community participation in preventing forest and land fires. The method used in this study is a survey method with data collection techniques in the field using questionnaires and interview techniques. The number of respondents in this study was 116 people from a population of 851 families. Data analysis used the Kendall Tau Correlation Non parametric statistical test. The results of research on community participation in preventing forest and land fires show the level of community participation at a moderate level, this is influenced by a close relationship between knowledge and understanding of the functions and benefits of preventing forest and land fires, knowledge can encourage people to take the initiative prevention with socialization and planning activities carried out by the local government. In the ladder of community participation according to Arnstein, Rasau Jaya II village is at the level of Therapy, which is a level of improvement, where there is no real participation, in this case the community is directly involved in a program, but community involvement is not based on a strong mental drive and participation that contributes to the program.
\end{abstract}

Keywords: Forest and land fires, Participation, Rasau Jaya, West Kalimantan

\section{PENDAHULUAN}

Hampir setiap tahun kebakaran lahan dan hutan terjadi di beberapa wilayah Indonesia. Intensitas dan luas cakupan kebakaran tidak ada perubahan secara signifikan. Hasil studi Forest Watch Indonesia (FWI) pada tahun 2003 menunjukkan bahwa pembukaan lahan dengan cara membakar hutan tidak terbatas pada Kalimantan dan Sumatera saja. Kebakaran dilaporkan terjadi di 23 dari 27 provinsi di Indonesia pada tahun 1997-1998. Sejumlah besar kebakaran hutan yang terjadi di kedua pulau utama tersebut disebabkan oleh perusahaan perkebunan dan berbagai proyek pemerintah, hal ini berakibat terhadap lenyapnya puluhan ribu hektare hutan pada satu kesempatan saja (PKHI 2014).

Setiap tahun pada saat musim kemarau sebagian besar wilayah Kalimantan Barat selalu diselimuti kabut asap yang berasal dari kegiatan pembakaran lahan atau kebakaran hutan dan lahan. Kabut asap yang ditimbulkan tidak hanya mengakibatkan penurunan kualitas udara di tingkat lokal. Kalimantan Barat juga ikut memberikan andil dalam penurunan kualitas udara di tingkat nasional dan bahkan regional ASEAN. 
Salah satu daerah yang rawan kebakaran hutan dan lahan di Propinsi Kalimantan Barat adalah desa Rasau Jaya kabupaten Kubu Raya yang setiap tahunnya terdeteksi titik-titik hotspot yang tinggi. Menurut Sunanto (2008) secara umum kondisi fisik Desa Rasau Jaya terdiri dari hutan dan lahan yang didominasi tanah bergambut serta mempunyai tingkat kelembaban tinggi dengan status guna lahan dan status hutan adalah kawasan pertanian lahan kering (PLK) atau areal penggunaan lain (APL). Meningkatnya pemukiman dan aktifitas perladangan serta pembukaan lahan secara tradisional dengan cara membakar, mengakibatkan Desa Rasau Jaya memiliki tingkat kerawanan kebakaran hutan dan lahan yang sangat tinggi. Penelitian mengenai partisipasi masyarakat dalam mencegah kebakaran hutan dan lahan ini diharapkan dapat merubah kebiasaan masyarakat agar lebih aktif dalam ikut serta untuk mencegah terjadinya kebakaran terutama pada lahan yang dijadikan masyarakat sebagai tempat untuk bercocok tanam. Kebakaran hutan dan lahan yang terjadi secara ekologi dapat merusak keadaan lingkungan disekitar tempat tinggal masyarakat maupun berdampak sangat luas. Untuk menunjang keberhasilan pencegahan kebakaran hutan dan lahan diperlukan partisipasi masyarakat sekitar karna keberhasilan bukan hanya peran dari Pemerintah namun sangat tergantung dari masyarakat itu sendiri.

Partisipasi merupakan keterlibatan mental dan emosi dari seseorang di dalam situasi kelompok yang mendorong mereka untuk menyokong kepada pencapaian tujuan kelompok tersebut dan ikut bertanggung jawab terhadap kelompoknya. pendapat lain menjelaskan bahwa partisipasi merupakan penyertaan pikiran dan emosi dari pekerja-pekerja kedalam situasi kelompok yang bersangkutan dan ikut bertanggung jawab atas kelompok itu

Penelitian ini bertujuan untuk menganalisis partisipasi masyarakat daerah Rasau Jaya II dalam mencegah kebakaran hutan dan lahan, serta menganalisis faktor-faktor yang berhubungan dengan partisipasi masyarakat dalam mencegah kebakaran hutan dan lahan di Desa Rasau Jaya II.

\section{METODE PENELITIAN}

Penelitian ini dilaksanakan di Desa Rasau Jaya II Kabupaten Kubu Raya yang terdiri dari 3 dusun yakni Dusun Banjar Sari, Banjar laut dan Banjar Rejo. Pengambilan data di lapangan secara efektif selama 3 minggu di mulai tanggal 1 November 2017. Alat yang digunakan dalam penelitian ini terdiri dari kuesioner, alat tulis-menulis, kamera, kalkulator,dan peta lokasi. Objek penelitian adalah masyarakat Desa Rasau Jaya II Kabupaten Kubu Raya. Jumlah responden dalam penelitian ini sebanyak 116 orang dari jumlah populasi sebanyak 851 KK. Metode pengambilan sampel responden pada penelitian ini adalah dengan teknik purposive random sampling. Adapun kriteria masyarakat yang akan dijadikan responden secara purposive sampling (teknik pertimbangan tertentu ) adalah warga desa setempat, berdomisili di dusun 
setempat minimal 5 tahun,usia minimal 17 tahun, dan bisa membaca dan menulis.
Untuk menentukan besarnya sampel dihitung dengan rumus Slovin sebagai berikut :

$$
n=\frac{N}{1+N e^{2}}
$$

Tabel 1. Daftar dan Jumlah Sampel

\begin{tabular}{ccc}
\hline Nama dusun & Jumlah KK & Purposive sampling \\
\hline Banjar Sari & 271 & 39 \\
Banjar Rejo & 375 & 40 \\
Banjar Laut & 205 & 37 \\
Jumlah & 851 & 116 \\
\hline
\end{tabular}

Keterangan:

$\mathrm{n}$ = Jumlah sampel responden

$\mathrm{N}=$ Jumlah populasi responden

e $=$ Batas toleransi kesalahan (15\%)

Penelitian ini menggunakan metode survey dengan teknik wawancara. Sedangkan pengkategorian variabel partisipasi, kosmopolitan, pengetahuan dan pendapatan berdasarkan rumus Standar Deviasi, yaitu:

Keterangan :

$$
\mathrm{SD}=\sqrt{\frac{n \sum x i^{2}-\left(\sum x i^{2}\right)}{n(n-1)}}
$$

$S D=$ Standar Deviasi $n \quad=$ Jumlah Responden

$\chi i=$ nilai $\mathrm{x}$ ke $i$

Dengan ketentuan sebagai berikut:

1. Sikap tinggi, jika sikap $>X+S D$

2. Sikap sedang, jika sikap $\mathrm{X}-\mathrm{SD}-<\mathrm{X}$ + SD

3. Sikap rendah, jika sikap $<\mathrm{X}-\mathrm{SD}$ Untuk perbandingan dengan teori Arnstein diketahui tingkat partisipasi masyarakat dengan menentukan skor mengacu dan mengikuti sebagaimana dipergunakan Meita (2015).

Tabel 2 .Skala skor Partisipasi Berdasarkan Teori Arnstein

\begin{tabular}{ccccccc}
\hline Jumlah & $\begin{array}{c}\text { Jumlah } \\
\text { Sample }\end{array}$ & $\begin{array}{c}\text { Skor } \\
\text { Pertanyaan }\end{array}$ & $\begin{array}{c}\text { Skor } \\
\text { maksimimum }\end{array}$ & $\begin{array}{c}\text { Tinkat } \\
\text { tangga } \\
\text { Arnstein }\end{array}$ & $\begin{array}{c}\text { Jarak } \\
\text { interval }\end{array}$ & Skor \\
\hline & & & & & &
\end{tabular}

(1)

(2)

(3)

(4)

(5)

$(116 \times 27=3132)-$

116

27

$27 \times 1=27$

$27 \times 5=135$

8

$(116 \times 135=15660$

18

$3132+1566$
Data yang dikumpulkan dianalisis dengan analisis deskriptif dan analisis inferensial. Analisis deskriptif digunakan untuk menganalisa data dengan cara mendeskripsikan atau menggambarkan data yang telah terkumpul sebagaimana adanya tanpa bermaksud membuat kesimpulan yang berlaku untuk umum atau generalisasi (Sugiyono, 2004) sedangkan analisis inferensial digunakan untuk menganalisis data sampel dengan maksud membuat kesimpulan yang berlaku umum atau generalisasi (Idrus, 2009). Analisis inferensial dalam penelitian ini digunakan untuk melihat 
hubungan variabel bebas terhadap variabel terikat. Model analisis inferensial yang digunakan dalam penelitian ini adalah uji statistik non parametrik korelasi Kendall Tau dengan bantuan program komputer (SPSS 16.0 For Windows).

\section{HASIL DAN PEMBAHASAN \\ Karakteristik Responden}

Karakteristik responden dalam penelitian ini berdasarkan tingkat umur, jenis kelamin, tingkat pendidikan dan jenis pekerjaan dapat dilihat pada tabel 3 berikut.

\section{Tabel 3. Karakteristik Responden Menurut Tingkat Umur, Jenis Kelamin,} Tingkat Pendidikan dan Jenis Pekerjaan.

\begin{tabular}{cccc}
\hline No & Identitas Responden & $\begin{array}{c}\text { Frekuensi } \\
\text { (Orang) }\end{array}$ & $\begin{array}{c}\text { Persentase } \\
(\mathbf{\%})\end{array}$ \\
\hline $\mathbf{A}$ & Umur & & 1.72 \\
1 & Muda & 2 & 47.41 \\
2 & Dewasa & 55 & 50.86 \\
3 & Tua & 59 & 100 \\
\hline B & Jumlah & 116 & 50 \\
1 & Jenis Kelamin & 50 \\
\hline 2 & Laki-laki & 58 & 100 \\
\hline Cerempuan & 58 & 37.93 \\
1 & Jumlah & 37.06 \\
2 & Pendidikan & 116 & 100 \\
3 & Tidak Sekolah-SD & 44 & \\
\hline \multicolumn{5}{c}{ SMP } & 43 & 49.13 \\
\hline 1 & SMA-Perguruan Tinggi & 29 & 24.13 \\
2 & Jumlah & 116 & 26.72 \\
\hline 3 & Pekerjaan & & 100 \\
\hline Sumber : Analisis Data & Petani & 57 &
\end{tabular}

Karakteristik responden berdasarkan tingkat umur dalam penelitian ini dikelompokkan menjadi tiga kategori yaitu muda pada kelompok umur 12-25 tahun, dewasa pada kelompok umur 26-45 tahun dan tua pada kelompok umur $>45$ tahun (Depkes 2009).

Berdasarkan hasil olahan data primer terhadap pengamatan di lapangan diperoleh frekuensi tingkat umur dengan kategori muda sebanyak 2 responden $(1,72 \%)$, kategori dewasa sebanyak 55 responden $(47.41 \%)$ dan kategori tua sebanyak 59 responden $(50.86 \%)$. jadi, umur responden masyarakat desa Rasau Jaya II didominasi oleh kategori tua atau dengan kelompok umur >45 tahun. hal tersebut memperlihatkan bahwa masyarakat dengan kategori tua lebih mengerti dan berpengalaman dalam memberikan keputusan.

Karakteristik responden berdasarkan jenis kelamin diperoleh frekuensi responden berjenis kelamin laki-laki sebanyak 58 responden $(50 \%)$ dan 58 responden $(50 \%)$ berjenis kelamin perempuan. karakteristik responden berdasarkan tingkat pendidikan dalam 
penelitian ini dikelompokkan menjadi tiga kategori (Anas 2009). Tingkat pendidikan rendah (tidak sekolah - SD), tingkat pendidikan sedang (SMP) dan tingkat pendidikan tinggi (SMA- Perguruan Tinggi). berdasarkan hasil olahan data primer terhadap pengamatan di lapangan diperoleh frekuensi tingkat pendidikan dengan kategori rendah sebanyak 44 responden (37,93\%), kategori sedang sebanyak 43 responden $(37,06 \%)$ dan kategori tinggi sebanyak 29 responden (25\%). jadi, tingkat pendidikan masyarakat di desa Rasau Jaya II berada pada kategori rendah yaitu tidak sekolahSD. hal ini terjadi karena masyarakat desa Rasau Jaya II masih kurang menyadari betapa pentingnya pendidikan atau sekolah, selain itu sebagian besar dari masyarakat desa Rasau Jaya II merupakan warga transmigrasi dari Pulau Jawa, sehingga ketika datang ke pulau Kalimantan warga tidak lagi mau menyambung sekolah melainkan memilih bekerja sebagai petani.

Karakteristik responden berdasarkan jenis pekerjaan dalam penelitian ini terbagi menjadi tiga yakni petani, pedagang dan lain lain (pegawai, buruh, swasta, dan ibu rumah tangga). berdasarkan hasil olahan data primer terhadap pengamatan di lapangan diperoleh frekuensi jenis pekerjaan petani sebanyak 57 responden (49.13\%), pedagang sebanyak 28 responden $(24.13 \%)$ dan lain-lain sebanyak 31 responden (26.72\%). masyarakat yang sebagian merupakan warga transmigrasi ini memilih bekerja mengikuti orang tuanya sebagai petani ataupun berkebun di lahan yang diberikan oleh pemerintah pada tahun 90-an . jadi, jenis pekerjaan yang mendominasi masyarakat desa Rasau Jaya II adalah petani. hal tersebut sudah jelas disebabkan karena banyaknya lahan kosong yang dapat dimanfaatkan masyarakat, maka dari itu masyarakat lebih memilih untuk bercocok tanam di lahan sendiri maupun memakai lahan milik orang lain untuk memenuhi kebutuhan hidup.

\section{Tingkat Partisipasi}

Berdasarkan frekuensi kelompok tingkat partisipasi masyarakat Desa Rasau Jaya II memiliki tingkat partisipasi yang bervariasi berdasarkan sampel penelitian terdapat 8 responden $(6.90 \%)$ yang tergolong dalam kelompok partisipasi rendah, 107 responden (92,24\%) yang tergolong dalam kelompok partisipasi sedang dan 1 responden $(0.86 \%)$ yang tergolong dalam kelompok partisipasi tinggi.

\section{Tabel 1. Frekuensi Responden Berdasarkan Tingkat Partisipasi}

\begin{tabular}{cccc}
\hline No & Partisipasi & Frekuensi (responden) & Persentase (\%) \\
\hline 1 & Tinggi & 1 & 0.86 \\
2 & $\begin{array}{c}\text { Sedang } \\
\text { S3.15) }\end{array}$ & 107 & 92.24 \\
3 & $\begin{array}{c}\text { Rendah } \\
(<43.13)\end{array}$ & 8 & 6.90 \\
\hline & Jumlah & 116 & 100
\end{tabular}

Sumber : Analisis Data 2017 


\begin{abstract}
Berdasarkan pengamatan yang telah dilakukan masyarakat yang memiliki tingkat partisipasi tinggi adalah masyarakat yang paling memiliki kesadaran tinggi untuk ikut aktif dalam pencegahan kebakaran hutan dan lahan, masyarakat sekitar sudah paham bagaimana pentingnya menjaga lingkungan dari kebakaran hutan dan lahan, antisipasi kebakaran hutan dan lahan telah diupayakan dilakukan pencegahan oleh masyarakat itu sendiri.
\end{abstract}

Masyarakat yang memiliki tingkat partisipasi sedang tersebut adalah masyarakat yang cukup mengetahui dengan baik mengenai keikut sertaan dalam mencegah kebakaran hutan dan lahan, dimana pengetahuan dan pemahaman tentang keikutsertaan mencegah kebakaran hutan dan lahan sangat direspon baik oleh masyarakat tersebut. sampai saat ini bentuk partisipasi yang dilakukan oleh masyarakat minimal dengan melaporkan kepada dinas terkait penanggulangan kebakaran hutan dan lahan jika terdapat atau terdeteksi titik api pada sekitar hutan dan lahan.

Masyarakat yang memiliki tingkat partisipasi rendah ialah masyarakat yang memiliki sikap acuh tak acuh terhadap keberadaan lingkungan. Sikap acuh tak acuh terhadap kebakaran hutan dan lahan ini disebabkan oleh beberapa faktor antara lain kecilnya tingkat kepedulian masyarakat terhadap lingkungan sekitarnya, kurang informasi mengenai pentingnya menjaga lingkungan dari kebakaran hutan dan lahan

Apabila dibandingkan dengan tangga partisipasi teori Arstein diperoleh data sebagai berikut:

Tabel 2. Penentuan Partisipasi Berdasarkan Teori Arnstein

\begin{tabular}{cll}
\hline No & Tingkat Partisipasi & Skor \\
\hline 1 & Manipulasi & $3132-4698$ \\
2 & Terapi & $4699-6265$ \\
3 & Pemberitahuan & $6266-7832$ \\
4 & Konsultasi & $7833-9399$ \\
5 & Pententraman & $9400-10966$ \\
6 & Kemitraan & $10967-12533$ \\
7 & Pelimpah kekuasaan & $12534-14100$ \\
8 & Control masyarakat & $14101-15667$ \\
\hline
\end{tabular}

Sumber: Hasil Olahan Data Primer 2017

Dari hasil penelitian skor yang diperoleh dari tabel tersebut bahwa jumlah skor dari masing-masing individu yang diteliti berjumlah 5584 dari 116 responden. tingkat partisipasi masyarakat berada pada tingkatan tangga ke- 2 (Dua) yaitu terapi. dalam tangga partisipasi menurut Arnstein tingkatan terapi ini merupakan

tingkatan perbaikan,dimana tidak terdapat partisipasi yang sesungguhnya, dalam hal ini masyarakat terlibat langsung dalam suatu program, namun keterlibatan masyarakat tidak didasari oleh suatu dorongan mental yang kuat dan keikutsertaan yang memberikan konstribusi dalam program tersebut. tingkat partisipasi yang masih dalam 
kategori terapi ini disebabkan karna belum adanya kegiatan aktif pembentukan Kelompok Peduli Api, dimana Kelompok Peduli Api ini sangat bermanfaat untuk meningkatkan keaktifan dan kepedulian masyarakat terhadap lingkungan sekitar dalam pencegahan kebakaran hutan dan lahan.

\section{Karakteristik Responden}

Berdasarkan Tingkat Kosmopolitan

Karakteristik responden dalam penelitian ini dikelompokkan menjadi tiga kategori, yakni tinggi, sedang dan rendah. Berdasarkan olahan data primer hasil pengamatan lapangan diperoleh kategori frekuensi tingkat kosmopolitan dengan kategori tinggi sebanyak 27 responden (23.28\%), kategori sedang sebanyak 78 responden $(67,24 \%)$ dan kategori rendah sebanyak 11 responden $(9,48 \%)$.

berdasarkan tingkat kosmopolitan

Tabel 3. Frekuensi Responden Berdasarkan Tingkat Kosmopolitan

\begin{tabular}{cccc}
\hline No & Pengetahuan & $\begin{array}{c}\text { Frekuensi } \\
\text { (responden) }\end{array}$ & Persentase (\%) \\
\hline 1 & $\begin{array}{c}\text { Tinggi } \\
(>23.95)\end{array}$ & 27 & 23.28 \\
2 & $\begin{array}{c}\text { Sedang } \\
(20.64-23.95) \\
\text { Rendah } \\
(<20.64)\end{array}$ & 78 & 67.24 \\
3 & Jumlah & 116 & 9.48 \\
\hline
\end{tabular}

\section{Sumber : Analisis Data 2017}

Berdasarkan pengamatan, tingkat kosmopolitan yang sedang tersebut disebabkan karena sebagian besar masyarakat Desa Rasau Jaya II mengetahui pemberitaan tentang dampak dari kebakaran hutan dan lahan, selain itu masyarakat juga sering mendapatkan sosialisasi terkait pencegahan kebakaran hutan dan lahan serta bagaimana cara mereka menggunakan lahan agar tidak menyebabkan kebakaran yang dapat merugikan masyarakat luas, sosialisasi ini diadakan oleh pemerintah Desa, gabungan TNI-POLRI serta Manggala Agni.

\section{Karakteristik Responden Berdasarkan Tingkat Pengetahuan}

Karakteristik responden berdasarkan tingkat pengetahuan dalam penelitian ini dikelompokkan menjadi tiga kategori yakni tinggi, sedang dan rendah. Berdasarkan olahan data primer hasil pengamatan lapangan diperoleh kategori frekuensi tingkat pengetahuan dengan kategori tinggi sebanyak 10 responden $(8,62 \%)$, kategori sedang sebanyak 89 responden $(76.72 \%)$ dan kategori rendah sebanyak 17 responden $(14,66 \%)$. Karakteristik responden berdasarkan tingkat pengetahuan selengkapnya tertera pada Tabel 4. 
Tabel 4. Frekuensi Responden Berdasarkan Tingkat Pengetahuan

\begin{tabular}{cccc}
\hline No & Pengetahuan & $\begin{array}{c}\text { Frekuensi } \\
(\text { responden })\end{array}$ & Persentase (\%) \\
\hline 1 & $\begin{array}{c}\text { Tinggi } \\
(>36.11)\end{array}$ & 10 & 8.62 \\
2 & $\begin{array}{c}\text { Sedang } \\
(31.53-36.11) \\
\text { Rendah } \\
(<31.53)\end{array}$ & 89 & 76.72 \\
3 & Jumlah & 17 & 14.66 \\
\hline
\end{tabular}

Sumber: Analisis Data 2017

Tingkat pengetahuan masyarakat Desa Rasau Jaya II berada pada kategori sedang disebabkan karena masyarakat Desa Rasau Jaya II sangat senang jika menerima informasi baru dari berbagai sumber, baik secara formal maupun informal. Masyarakat sekitar juga mengetahui pentingnya menjaga lingkungan agar terjaga dari kebakaran hutan dan lahan.

Masyarakat desa Rasau Jaya II sangat sering mendapatkan segala informasi tentang bagaiamana cara untuk melakukan pencegahan kebakaran hutan dan lahan. namun masyarakat masih ada yang selalu berfikiran yang kurang maju tentang bagaimana membakar hutan dan lahan dengan baik mereka terkadang masih tidak menghiraukan jika ada informasi

penyuluhan yang diberikan sehingga masih adanya tingkat pengetahuan masyarakat dalam kategori tingkat rendah.

\section{Karakteristik Responden \\ Berdasarkan Tingkat Pendapatan}

Karakteristik

responden

berdasarkan tingkat pendapatan dalam penelitian ini dikelompokkan menjadi tiga kategori, yakni tinggi, sedang dan rendah. Berdasarkan olahan data primer hasil pengamatan lapangan diperoleh kategori frekuensi tingkat pendapatan dengan kategori tinggi sebanyak 29 responden $(25 \%)$, kategori sedang sebanyak 70 responden $(60,34 \%)$ dan kategori rendah sebanyak 17 responden $(14,66 \%)$. Karakteristik responden berdasarkan tingkat pendapatan selengkapnya disajikan pada Tabel 5 .

Tabel 5. Frekuensi Responden Berdasarkan Tingkat Pendapatan

\begin{tabular}{cccc}
\hline No & Pendapatan & $\begin{array}{c}\text { Frekuensi } \\
(\text { responden })\end{array}$ & Persentase (\%) \\
\hline 1 & Tinggi & 29 & 25 \\
$(>2.890 .000)$ & & 60.34 \\
2 & $\begin{array}{c}\text { Sedang } \\
(1.711 .000- \\
2.890 .000) \\
\text { Rendah } \\
3\end{array}$ & 70 & 14.66 \\
\hline$<1.711 .000)$ & 17 & 100 \\
\hline
\end{tabular}

Sumber Analisis Data 2017

Berdasarkan data diatas menunjukan bahwa pendapatan masyarakat desa Rasau Jaya II memiliki tingkat pendapatan yang sedang 
dikarenakan pendapatan masyrakat sekitar didapat dari bekerja sebagai petani ataupun pedagang, sedangkan pendapatan kelompok lain didapat dari pekerjaan lain seperti pegawai negri, buruh dan lain-lain. Hal ini karna tingkat pekerjaan masyarakat mempengaruhi tingkat pendapatan masyarakat setempat.data diatas menunjukan bahwa seluruh kelompok pendapatan cenderung memiliki partisipasi yang cukup baik dalam pencegahan kebakaran hutan dan lahan. karena baik pendapatan kecil ataupun besar tetap berpengaruh pada kehidupan mereka.

Tabel 6. Hasil Uji Statistik Kendall Tau

\section{Hubungan Variabel Terikat dan Variabel Bebas}

Variabel terikat dalam penelitian ini adalah partisipasi masyarakat desa Rasau Jaya II kabupaten Kubu Raya dalam mencegah kebakaran hutan dan lahan, sedangkan variabel bebas adalah tingkat pengetahuan, tingkat kosmopolitan, tingkat pendapatan. Idrus (2009) mengatakan bahwa analisis inferensial adalah analisis yang dilakukan menggunakan uji statistik serta digunakan untuk menganalisis data sampel dengan maksud membuat kesimpulan yang berlaku umum atau generalisasi.

\begin{tabular}{|c|c|c|c|c|c|}
\hline \multirow[b]{2}{*}{ No } & \multirow[b]{2}{*}{ Variabel } & \multicolumn{3}{|c|}{ Sikap } & \multirow[b]{2}{*}{ Keterangan } \\
\hline & & $\mathbf{N}$ & $\begin{array}{r}\text { Correlation } \\
\text { Coefficient }\end{array}$ & $\begin{array}{c}\text { Sig. } \\
\text { (2-tailed) }\end{array}$ & \\
\hline 1. & Tingkat pengetahuan & 116 & 0.269 & 0.000 & $\begin{array}{l}\text { Signifikan } \\
\text { Tidak }\end{array}$ \\
\hline 2. & Kosmopolitan & 116 & -0.053 & 0.465 & $\begin{array}{l}\text { Signifikan } \\
\text { Tidak }\end{array}$ \\
\hline 3. & Pendapatan & 116 & -0.020 & 0.776 & Signifikan \\
\hline
\end{tabular}

Sumber: Analisis Data Primer, 2017

Hubungan partisipasi masyarakat dengan dengan tingkat pengetahuan

Hasil uji statistik korelasi Kendall

Tau antara partisipasi masyarakat dalam mencegah kebakaran hutan dan lahan dengan tingkat pengetahuan diperoleh nilai Sig.(2-tailed) 0,000 lebih kecil dari taraf signifikan 5\% atau nilai Sig 0,000 $<0,05$ dengan koefisien korelasi positif sebesar 0,269. Disimpulkan terdapat hubungan yang signifikan antara partisipasi masyarakat dalam mencegah kebakaran hutan dan lahan dengan tingkat pengetahuan. Hal tersebut disebabkan karena kemampuan masyarakat dalam memperoleh ilmu dan informasi terkait pencegahan kebakaran hutan dan lahan dengan cara membakar baik melalui jalur formal maupun informal cukup baik. Nilai koefisien korelasi positif menunjukan bahwa semakin positif atau tinggi tingkat pengetahuan masyarakat terhadap partisipasi mencegah kebakaran hutan dan lahan, maka partisipasi masyarakat dalam mencegah kebakaran hutan dan lahan akan cenderung lebih tinggi. Masyarakat Desa Rasau Jaya II yang mayoritasnya bekerja sebagai petani dan berkebun mereka memiliki pengethuan yang cukup baik dalam mengelola tanah, pengetahuan itu didapatkan mereka dari 
sosialisai yang diberikan pemerintah maupun organisasi setempat.

Seperti halnya pencegahan terhadap kebakaran hutan dan lahan, masyarakat sekitar selalu membuat embung/kolam yang berisi air, itu dilakukan agar jika suatu saat terjadinya kebakaran di lahan yang mereka tanami setidaknya tersedia air yang cukup untuk membahasi lahan yang terkena kebakaran,usaha kecil yang dilakukan masyarakat setidaknya sudah membantu dalam mencegah kebakaran agar tidak terjadi lebih luas.

\section{Hubungan Partisipasi Masyarakat dengan Tingkat Kosmopolitan}

Hasil uji statistik korelasi Kendall Tau antara partisipasi masyarakat dalam mencegah kebakaran hutan dan lahan dengan tingkat kosmopolitan masyarakat diperoleh nilai Sig.(2-tailed) 0,465 lebih kecil dari taraf signifikan $5 \%$ atau nilai Sig 0,465 $<0,05$ dengan koefisien korelasi negatif sebesar 0,053. Disimpulkan, tidak terdapat hubungan yang signifikan antara partisipasi masyarakat dalam mencegah kebakaran hutan dan lahan dengan tingkat kosmopolitan masyarakat. Nilai koefisien korelasi negatif menunjukan bahwa semakin negatif atau rendah tingkat kosmopolitan masyarakat terhadap pencegahan kebakaran hutan dan lahan, maka partisipasi masyarakat dalam mencegah kebakaran hutan dan lahan akan cenderung rendah atau sedang. Berdasarkan hasil pengamatan diketahui bahwa tingkat kosmopolitan masyarakat terhadap partisipasi dalam mencegah kebakaran hutan dan lahan sebagian besar $(67,24 \%)$ cenderung sedang, sedangkan partisipasi masyarakat dalam mencegah kebakaran hutan dan lahan sebagian besar (92.24 $\%$ ) cenderung sedang.masyarakat sekitar sebenarnya dapat menerima informasi dengan sangat cepat karena adanya sosialisasi yang diberikan, namun Upaya pencegahan dan penanggulangan yang telah dilakukan selama ini terkadang belum memberikan hasil yang optimal dan kebakaran hutan dan lahan masih terus terjadi pada setiap musim kemarau hal ini disebabkan karna masih adanya masyarakat yang meiliki kesadaran yang kurang dalam mengetahui dampak dari kebakaran.

\section{Hubungan partisipasi masyarakat dengan dengan tingkat pendapatan}

Hasil uji statistik korelasi Kendall Tau antara partisipasi masyarakat dalam mencegah kebakaran hutan dan lahan dengan tingkat pendapatan masyarakat $r$ diperoleh nilai Sig. (2-tailed) 0,776 lebih kecil dari taraf signifikan $5 \%$ atau nilai Sig 0,776 < 0,05 dengan koefisien korelasi negatif sebesar 0,020. Disimpulkan, tidak terdapat hubungan yang signifikan antara partisipasi masyarakat dalam mencegah kebakaran hutan dan lahan dengan tingkat pendapatan masyarakat.

Hasil pengamatan yang dilakukan di lapangan bahwa rata-rata pendapatan masyarakat Desa Rasau Jaya II cenderung sedang $(60,34)$, dimana masyarakat sekitar mayoritas bekerja sebagai petani atau pun berkebun, Sebagian besar masyarakat sangat mengandalkan lahan yang ada untuk 
dijadikan pertanian. Menurut hasil pengamatan yang dilakukan masyrakat yang bekerja sebagai pegawai di kantor desa, mereka tetap masih bekerja sebagai petani untuk memenuhi kebutuhan hidup mereka. Seperti halnya Penelitian Lingani et al., (2011) mengungkapkan bahwa pendapatan mempengaruhi partisipasi masyarakat dalam pengelolaan hutan.

\section{Kesimpulan}

1. Partisipasi masyarakat dalam mencegah kebakaran hutan dan lahan di desa Rasau Jaya II kabupaten Kubu Raya didapatkan 107 responden $(92,24 \%)$ yang memiliki tingkat partisipasi cenderung sedang namun dibandingkan dengan teori Arnstein partisipasi masyarakat masih berada pada tangga ke 2(dua) atau terapi.

2. Terdapat hubungan yang signifikan antara partisipasi masyarakat dalam mencegah kebakaran hutan dan lahan di Desa Rasau Jaya II Kabupaten Kubu Raya dengan pengetahuan.

3. Tidak terdapat hubungan yang signifikan antara partisipasi masyarakat dalam mencegah kebakaran hutan dan lahan di Desa Rasau Jaya II Kabupaten Kubu Raya dengan Kosmopolitan dan tingkat pendapatan.

\section{Saran}

Berdasarkan hasil penelitian partisipasi masyarakat ini terlihat bahwa tingkat partisipasi masyarakat masih tergolong dalam kategori perbaikan, dimana belum terdapat keikutsertaan masyarakat yang memberikan kontribusi yang baik, dalam hal ini hendaknya masyarakat diharapkan mempunyai dorongan yang kuat untuk terlibat dalam keikut sertaan dalam mencegah kebakaran hutan dan lahan, selain itu lembaga yang terkait hendaknya dapat bekerjasama dengan masyarakat dengan menjalankan kegiatan yang bertahap, dengan di mulai dari perencanaan, pelaksanaan, serta pengawasan, dengan kegiatan yang melibatkan masyarakat akan membuat komunikasi antara masyarakat menjadi aktif antara semua pihak dan akan mendukung partisipasi aktif di dalamnya.

\section{DAFTAR PUSTAKA}

Ahmadi, Abu. 2003. Ilmu Pendidikan. Rineka Cipta. Jakarta

Anas sudijono. (2009). Pengantar evaluasi pendidikan. Jakarta: Rajagrafindo.

Arnstein, Sherry. 1969. A Ladder of Citizen Participation. Journal of the American Institute of Planners

Chandler C, P Cheney, P Thomas P, L Trabaud L, D Williams. 1983. Fire in Forestry Vol. I. Jhon Wiley and Sons. Canada.

Cohen and Uphoff. 1977. Rural Development Participation. Cornel University. New York

Darwiati, W. dan F.D. Tuheteru. 2010. Dampak kebakaran hutan terhadap pertumbuhan vegetasi. Jurnal Mitra Hutan Tanaman. 3(1): 27-32. (http://fordamof.org/files/Tekno_HT_3.1.2010 
5.Wida_Darwiati_n_Faisal_Danu .pdf diakses tanggal 21 april 2017)

Deepa, Narayan. 1995. The Contribution of People's Participation, Evidence from 121 Rural Water Supply Project. The World Bank, 1995. (http:// www.kelair.bppt.go.id/Hukum/dat a/kebijakan/AMPL/ind/index_pus. htm diakses tanggal 23 april 2017)

Departemen Kesehatan RI. 2009. Kategori Usia. (http://kategoriumurmenurut-Depkes.html.

Diakses Pada Tanggal 20 November 2017)

Fasli Lalal dan Dedi Supriadi. 2001. Reformasi Pendidikan Dalam Konteks otonomi Daerah. Yogyakarta: Adicita.

Fauzi, H. 2012. Pembangunan HutanBerbasis Masyarakat Kehutanan Sosial. Karya Putra Darwati. Bandung.

FWI Forest Watch Indonesia. 2003. Potret Keadaan Hutan Indonesia. Forest Watch Indonesia dan Washington D.C, Global Forest Watch, Edisi 3. Bogor. Indonesia. (http://repository.usu.ac.id/bitstre am/123456789/34714/2/Reference .pdf diakses pada tanggal 22 april 2017)
Hatta, M. 2008. Dampak kebakaran hutan terhadap sifat-sifat tanah di Kecamatan Besitang Kabupaten Langkat. Draft Hasil Penelitian. Departemen Kehutanan Fakultas Pertanian Universitas Sumatera Utara.

Idrus, M. 2009. Metode Penelitian Ilmu Sosial-Pendekatan Kualitatif dan Kuantitatif Edisi Kedua. Erlangga. Yogyakarta.

Keraf, AS., 2002. Etika Lingkungan, Penerbit Buku Kompas, Jakarta

Meita. 2015. Partisipasi Masyarakat Dalam Pengelolaan Hutan Adat di Dusun Sungai Utik Desa Batu Lintang Kecamatan Emabaloh Hulu Kabupaten Kapuas Hulu. [Skripsi]. Fakultas Kehutanan Universitas Tanjung Pura

Sunanto.2008. Peran Serta Masyarkat dalam Pencegahan dan Penanggulangan Kebakaran Lahan di Kecamatan Rasau Jaya. [tesis]. Semarang. Program Pasca Sarjana Universitas Diponegoro

Sugiyono. 2013. Metode Penelitian Pendidikan Pendekatan Kuantitatif, Kualitatif, dan $R \& D$. Bandung: Alfabeta. (http://eprints.ums.ac.id/42448/16 /DAFTAR\%20PUSTAKA.pdf diakses pada tanggal 21 april 2017) 